\title{
Why probiotics yogurt is beneficial to HIV/AIDS patients?
}

Ying Zhang, ${ }_{1}$ Man Tang, ${ }^{2}$ Yuan Wang, ${ }^{2}$ Min Fu, ${ }^{3}$ Jess Lan Ouyang, ${ }^{2}$ Qiuyun Liu ${ }^{2}$

${ }^{1}$ Guangzhou Center for Disease Control and Prevention, Guangzhou 510440, China.

${ }^{2}$ School of Life Sciences, Sun Yat-sen University, Guangzhou 510275, China.

${ }^{3}$ Deyang Health Committee, Sichuan, China.

Correspondence: Qiuyun Liu, Ph.D, School of Life Sciences, Sun Yat-sen University, Guangzhou 510275, China

e-mail: 1sslqy@mail.sysu.edu.cn 


\begin{abstract}
AIDS patients often display symptom of diarrhea, an indication of hydrogen bonding mediated by viral proteins with amino acids capable of secondary chemical bonding. With hydrogen bonding to protons, local strong acids such as $\mathrm{HCl}$ could build up, giving rise to proton stress which may damage cells or trigger tumorigenesis. Weak organic acids counteract strong acids and attenuate proton stress. The integration of antiviral medicine with probiotics could yield favorable outcomes to AIDS patients and meanwhile reduce cancer incidences.
\end{abstract}

Keywords

AIDS; probiotics; yogurt; hydrogen bonding; tumorigenesis 
Beneficial gut microbiota in HIV patients can be restored via the use of probiotics. ${ }^{1}$ AIDS patients often display symptom of diarrhea ${ }^{2-5}$, an indication of hydrogen bonding mediated by viral proteins with amino acids capable of secondary chemical bonding. With hydrogen bonding to protons, local strong acids such as $\mathrm{HCl}$ could build up, giving rise to proton stress which may damage cells or trigger tumorigenesis. ${ }^{6-15}$ For instance, the humid southern coastal China and Southeast Asia are high in nasopharyngeal carcinoma incidences, whereas the non-humid and non-coastal Yunnan Province in south China is low in nasopharyngeal cancer prevalence. ${ }^{6-7}$ Weak organic acids counteract strong acids and attenuate proton stress. Consumption of yogurt has demonstrated numerous benefits to AIDS patients. ${ }^{1}$ Probiotic yogurt intake is correlated with an increase of $\mathrm{CD}_{4}$ cell count in individuals with HIV/AIDS. ${ }^{2}$ Calcium supplement can neutralize strong acids and reduce cancer risks ${ }^{16-17}$, which could improve patients' conditions. Plant-based diet is rich in weak organic acids and elicits health-protecting effects. ${ }^{18-19}$ The reduced intake of salt is desirable as the overconsumption of $\mathrm{NaCl}$ may enhance the local formation of mutagenic $\mathrm{HCl}^{6}{ }^{6}$ Red meat is characterized by the presence of myoglobin which harbors $19-21 \%$ positively charged basic amino acids which attract $\mathrm{Cl}^{-} .6,20$ Therefore the overconsumption of red meat and processed meat is a concern to people with HIV/AIDS. The integration of antiviral medicine with probiotics could yield favorable outcomes to AIDS patients and meanwhile reduce cancer incidences. Furthermore, the effects of supplement with probiotics rich in weak organic acids can be investigated to find out whether or not the attenuation of proton stress confers a positive effect on the efficacy of vaccination.

\section{Acknowledgements}

We thank grant support from the Science and Technology Transformation Program of Sun Yat-sen University of China (33000-18843234) and Guangzhou Science and Technology Program (201804010328) to Q. Liu; National Science and Technology Major Project of the Ministry of Science and Technology of China (2017ZX10103011) to Y. Zhang. We are grateful to Yan Shi for editing.

\section{Author Disclosure Statement}

No competing financial interests exist.

References:

1. Ashuro AA, Lobie TA, Ye DQ, Leng RX, Li BZ, Pan HF, Fan YG. Review on the Alteration of Gut Microbiota: The Role of HIV Infection and Old Age. AIDS Res Hum Retroviruses 2020;36(7): 556-565.

2. Anukam KC, Osazuwa EO, Osadolor HB, Bruce AW, Reid G. Yogurt containing probiotic Lactobacillus rhamnosus GR-1 and L. reuteri RC-14 helps resolve moderate diarrhea and increases CD4 count in HIV/AIDS patients. J Clin Gastroenterol 2008;42(3): 239-243.

3. Mönkemüller KE, Wilcox CM. Investigation of diarrhea in AIDS. Can J Gastroenterol. 2000;14(11): 933-940. https://doi.org/10.1155/2000/610878 
4. Whaling MA, Luginaah I, Reid G, Hekmat S, Thind A, Mwanga J, Changalucha J. Perceptions about probiotic yogurt for health and nutrition in the context of HIV/AIDS in Mwanza, Tanzania. J Health Popul Nutr. 2012;30(1): 31-40. https://doi.org/10.3329/jhpn.v30i1.11273

5. Reid G. The potential role for probiotic yogurt for people living with HIV/AIDS. Gut microbes. 2010; 1(6): 411-414. https://doi.org/10.4161/gmic.1.6.14079

6. Wan Y, Zhang J, Li X, Wang Y, Liu Q. Cellular States and Secondary Chemical Bonding: A Biochemical View of Major Human Diseases. Biochem Insights. 2019; 12: 1178626419877846.

7. Wan Y, An S, Zhou Y, Tang M, Liu Q. A solo dance or a tango? Biochem Insights. 2019; 12: 1178626419886280.

8. Tang M, Zhou Y, Li Y, et al. Hydrogen donors and acceptors and basic amino acids jointly contribute to carcinogenesis. Med Hypotheses. 2017;98:42-44. doi: 10.1016/j.mehy.2016.11.014

9. Zhang J, Tang M, Shi Y, et al. Appearance of somatic mutations can be subjected to the influences of inherited factors. Science. 2017. http://science.sciencemag.org/content/355/6331/1330/tab-e-letters

10. An S, Li X, Tang M, Xing M, Zhang Y, Peng J, Xu L, Liu Q. The Role of Acetate in the Antagonization of Oxalate: A Potential Causative Molecule for Heart Disease and Cancer Death. Nat Prod Commun 2020;15:1934578X2091369.

11. Wan Y, Ma X, Li Y, Huang X, Gan T, Xu L, Cao W, Liu Q. Local strong acids: A driving force for metastasis. Med Hypotheses.2020; 144: 110221.

12. Wan Y, Wen L, Liu Q. Who will benefit from colorectal cancer prevention measures? Eur J Cancer Prev. 2019;28(5): 459-460.

13. Wan $\mathrm{Y}, \mathrm{Hu} \mathrm{X}$, Liu Q. Protection of cancer in patients with neurodegenerative diseases. Eur J Cancer Prev. 2019;28: 459.

14. Shi Y, An S, Wan Y, Yang F, Liu Q. How to best use acetic acid for the prevention of heart disease and cancer. Eur J Prev Cardiol. 2019; 26: 437-438.

15. Wan Y, Li J, Liu Q. Vinegar production and cancer risk. Eur J Cancer Prev. 2019;28(4): 382.

16. An S, Yan S, Zhang Y, Xu H, Gan T, Liu Q. Is It Possible to Establish a Tumor-Suppressive Microenvironment With Glycine and Valine Supplement? Cancer Control. 2020;27(1): 1073274820954453.

17. Wactawski-Wende J, Kotchen JM, Anderson GL, et al. Calcium plus vitamin D supplementation and the risk of colorectal cancer. New Engl J Med. 2006; 354: 684-696.

18. Zhou Y, Shi Y, Wan Y, et al. Why the Mediterranean diet lowers the risk of heart disease. Eur J Prev Cardiol. 2017;24: 1788-1789.

19. Gan T, Cheng D, Qiuyun Liu Q. Principle anticancer substances in plant-based $\begin{array}{llll}\text { diet and } & \text { fruits. }\end{array}$ http://science.sciencemag.org/content/349/6253/1167/tab-e-letters

20. Wan Y, An S, Zhou Y, Zhang J, Zhang Y, Gan T, Liu Q. Is weak acid beneficial for addressing checkpoint inhibitor-triggered cancer hyperprogression in 
anti-PD1/PD-L1

immunotherapies?

Cancer

Control

2020;27:

1073274820944290. 